\title{
ALGUÉM SABE? ALGUÉM VIU? QUAL O LUGAR DA HISTÓRIA E CULTURA AFRICANA E AFRO-BRASILEIRA E EDUCAÇÃO DAS RELAÇÕES ÉTNICO-RACIAIS NOS CURSOS DE LICENCIATURA NA REGIÃO DO CENTRO-OESTE?
}

\author{
Cíntia Santos Diallo \\ Claudia Araújo de Lima
}

\begin{abstract}
RESUMO
O presente artigo tem como objetivo expor os resultados preliminares da pesquisa em desenvolvimento no Programa de Pós-Graduação em Educação da Universidade Federal de Mato Grosso do Sul, Campus Pantanal, sobre a incorporação dos conteúdos referentes à História e Cultura afro-brasileira e africana e à Educação para Relações Étnico-raciais nos currículos dos cursos de Licenciatura da área de Ciências Humanas das Instituições Federais Públicas de Ensino Superior da região do Centro-Oeste, no período de 2003 a 2017. Em diálogo com a História da Educação e com a Decolonialidade, são analisados 104 cursos de licenciatura, dos quais 50 contemplam, em suas matrizes curriculares, conteúdos referentes à História e Cultura afro-brasileira e africana e à Educação das Relações Étnico-raciais, com destaque para os cursos de História, uma vez que todos eles oferecem pelo menos uma disciplina sobre o assunto. O gritante silenciamento que ocorre em 48 cursos relacionados com a temática objeto da pesquisa explica, em parte, o recorrente discurso dos professores da Educação Básica sobre a fragilidade de sua formação inicial para discuti-la.
\end{abstract}

Palavras-chave: História Africana e Afro-brasileira. Relações Étnico-raciais. Formação de Professores.

\section{ANYBODY KNOW? SOMEONE SAW? WHAT IS THE PLACE OF AFRICAN, AFRO-BRAZILIAN HISTORY AND CULTURE, EDUCATION OF ETHNO-RACIAL RELATIONS IN UNDERGRADUATE COURSES IN MIDWEST?}

\begin{abstract}
The present article aims to present the preliminary results of the research, under development in the Postgraduate Program in Education, Federal University of Mato Grosso do Sul, Campus Pantanal, on the incorporation of the contents referring to Afro-Brazilian and African History and Culture and

\footnotetext{
${ }^{1}$ Pós-Doutoranda em Educação - Área de Concentração Educação Social na Universidade Federal de Mato Grosso do Sul/Campus do Pantanal (UFMS/CPAN). Doutora em História - Ensino da História da África (UFGD-2017), Mestre em Educação - Políticas Públicas para Educação (UNISUL/2005), licenciada em História e Pedagogia. Professora colaboradora da Universidade Estadual do Mato Grosso do Sul - UEMS desde 2009. Organizadora e autora do livro História da África Múltiplas Aprendizagens. Bolsista PNPD/CAPES. Vice-líder Grupo Gepegre. Área de Pesquisa Ensino e História da África, Educação das Relações Étnico-Raciais e Política Pública em Educação

${ }^{2}$ Doutora em Saúde Pública pela Escola Nacional de Saúde Pública/Fundação Oswaldo Cruz (2014), Mestre em Saúde Pública pela Escola Nacional de Saúde Pública/Fundação Oswaldo Cruz (2004), possui graduação em Pedagogia. Professora Adjunta na Universidade Federal de Mato Grosso do Sul - UFMS/Campus do Pantanal Coordenadora do Núcleo de Estudos e Pesquisas Interdisciplinares em Políticas Públicas, Direitos Humanos, Gênero, Vulnerabilidades e Violências - NEPI/PANTANAL/Brasil. Área de Ensino e Pesquisa: Educação Social, Metodologias da Pesquisa Social, Direitos Humanos, Metodologias Ativas de Ensino Aprendizagem, Educação e Diversidade, Gênero e Sexualidade, Violência contra Crianças e Adolescentes, Violência contra Mulheres e Estudos sobre Feminicídio.
} 
Education for Ethnic-Racial Relations to the curricula of the degree courses of the Human Sciences area of the Public Federal Higher Education Institutions of the Central-West region, from 2003 to 2017. In dialogue with the History of Education and with Decoloniality 104 undergraduate courses are analyzed, of which 50 courses include in their curricular matrices contents related to Afro-Brazilian and African History and Culture and Ethnic-Racial Relations Education, with emphasis on History courses, as they all offer at least one discipline on the subject. The stark silencing of 48 courses in relation to the subject matter of the research explains in part the recurrent discourse of Basic Education teachers about the fragility in their initial formations to discuss thematic.

Keywords: African and Afro-Brazilian History. Ethnic-Racial Relations. Teacher Training.

\title{
¿ALGUIEN LO SABE? ¿ALGUIEN LO HA VISTO? ¿CUÁL ES EL LUGAR DE LA HISTORIA Y LA CULTURA AFRICANA Y AFROBRASILEÑA Y DE LA EDUCACION DE RELACIONES ETNICO- RACIALES EN CURSOS DE LICENCIATURA EN LA REGION DEL MEDIO OESTE?
}

\begin{abstract}
RESUMEN
Este artículo tiene como objetivo exponer los resultados preliminares de la investigación en desarrollo en el Programa de Posgrado en Educación de la Universidad Federal de Mato Grosso do Sul, Campus Pantanal, sobre la incorporación de contenidos relacionados con la historia y cultura afrobrasileña y africana e a Educación para las relaciones étnico-raciales en el plan de estudios de los cursos de grado de Humanidades de las instituciones públicas federales de educación superior de la región del Medio Oeste, de 2003 a 2017. En diálogo con la historia de la educación y la descolonialidad, se analizan 104 cursos de pregrado, de los cuales 50 incluyen, en sus matrices curriculares, contenidos relacionados con la historia y cultura afrobrasileña y africana y la educación de las relaciones étnico-raciales, con énfasis en los cursos de historia, ya que todos ofrecen al menos una disciplina sobre el tema. El deslumbrante silenciamiento que ocurre en 48 cursos relacionados con el tema de investigación explica, en parte, el discurso recurrente de los maestros de Educación Básica sobre la fragilidad de su formación inicial para discutir tema tan importante y esencial
\end{abstract}

Palabras clave: Historia africana y afrobrasileña, Relaciones étnico-raciales, Formación docente.

\section{INTRODUÇÃO}

O presente artigo tem como objetivo expor os resultados preliminares da pesquisa em desenvolvimento no Programa de Pós-Graduação em Educação da Universidade Federal de Mato Grosso do Sul, Campus Pantanal ${ }^{3}$, sobre a incorporação dos conteúdos referentes à História e Cultura afro-brasileira e africana e à Educação para Relações Étnico-raciais ${ }^{4}$ nos currículos dos cursos de Licenciatura da área de Ciências Humanas das Instituições Federais Públicas de Ensino Superior da região do Centro-Oeste, no período de 2003 a 2018. Partimos

\footnotetext{
3 Atividade obrigatória do estágio pós-doutoral.

4 Deve ser estruturada a partir dos seguintes princípios: consciência política e histórica da diversidade; fortalecimento de identidades e de direitos; ações de combate ao racismo e a discriminações (Brasil, 2004, p.17). 
da Lei $10.639 / 2003^{5}$, que, ao tornar obrigatório o ensino da temática em tela para a Educação Básica pública e privada, demandou não só dos sistemas de ensino a oferta de cursos de formação continuada, mas também dos cursos de formação inicial de professores, das Licenciaturas e da reorganização de suas matrizes curriculares, a fim atualizar seus acadêmicos para agregar suas futuras práticas pedagógicas, os saberes, as narrativas e os modos de ser, estar e sentir até então negligenciados, subalternizados e, em muitos casos, invisibilizados pelo currículo acadêmico.

À lei somam-se as orientações das Diretrizes Curriculares Nacionais para a Educação das Relações Étnico-raciais e para o Ensino de História e Cultura Afro-brasileira e Africana (DCNERER, 2004) e do Plano de Implantação dessas Diretrizes, destinado aos professores, escolas, universidades e sistemas de ensino. Além disso, há as reivindicações dos professores em efetivo exercício nas redes públicas e privadas por cursos de extensão e especialização que abarquem a temática.

A Interculturalidade Crítica é a perspectiva pela qual se compreende a temática que, por um lado, permite a compreensão e a denúncia da racialização da sociedade, inaugurada pela Modernidade Ocidental, assim como seus desdobramentos, a subalternização e a inferiorização que a matriz europeia exerce sobre maneiras outras de ser, viver e saber. Por outro, ela possibilita a articulação, o diálogo, o respeito, o reconhecimento, a valorização e a superação da hierarquização dos conhecimentos, narrativas e saberes, ao conduzir a outras maneiras de entender e intercambiar histórias e culturas até então negadas, estigmatizadas e periféricas (WALSH, 2009).

A pesquisa está calcada na abordagem qualitativa, pois a temática está inserida em um "universo de significados, motivos, aspirações, crenças, valores e atitudes" que correspondem ao espaço mais profundo e denso das relações raciais, cujos "fenômenos não podem ser reduzidos à operacionalização de variáveis” (MINAYO, 1994, p.21 e 22). Assim, buscam-se respostas nas vivências, nas disputas por projetos de educação e sociedade, nas relações raciais e nas experiências da ação humana que se entrelaçam cotidianamente nas IES federais públicas. Isso para se compreender em que medida a História e Cultura Afro-brasileira e Africana e a Educação para Relações Raciais foram pelas Instituições incorporadas. Indo além, há que se verificar se a temática alcançou centralidade, se é periférica nos cursos, ou ainda se as matrizes

\footnotetext{
${ }^{5}$ É fruto da reivindicação do Movimento Negro desde a década de 1930, quando Abdias do Nascimento líder do Teatro Experimental do Negro - TEN, em suas reflexões sobre a condição do negro no Brasil, apontava a inclusão da história do negro no Brasil nos currículos escolares como uma, das muitas estratégias, para Promoção da Igualdade Racial no Brasil. (DOMINGUES, 2007)
} 
destes estão subordinadas à matriz europeia de produção no que tange à difusão e escolha do que é ou não conhecimento científico.

O caminho percorrido para atingir os objetivos da pesquisa envolveu vários movimentos, a começar pela delimitação temporal, que se estende de 2003, ano de promulgação da Lei 10.639/2003, até 2018, ano do estabelecimento das Bases Nacionais Curriculares Nacionais para o Ensino Fundamental. Quanto à delimitação espacial, o foco são as IES da região Centro-Oeste, uma vez, que pelos estudos anteriores ${ }^{6}$ ao estágio pós-doutoral circunscritos ao Estado de Mato Grosso do Sul, percebe-se que as discussões a respeito da incorporação da temática nos cursos de licenciatura são incipientes na região. $\mathrm{O}$ processo investigativo exigiu também a pesquisa bibliográfica e documental, a identificação das IES e a opção pelas federais, bem como a enumeração dos cursos de licenciatura e a seleção das disciplinas.

Para complementar a análise, foi elaborado um questionário semiestruturado, destinado aos professores em efetivo exercício, que será analisado na segunda fase da pesquisa. Os dados obtidos por meio do questionário são entendidos como possibilidades de acesso a informações de difícil identificação por outros caminhos investigativos, como, por exemplo, experiências e impressões pessoais particulares dos envolvidos no processo (ALBERTI, 2004).

Com o auxílio da análise de conteúdo, buscam-se, nos questionários, respostas para os questionamentos que norteiam a pesquisa, e ainda desvelar o que está por trás dos conteúdos manifestos, superando o aparecer imediato do que está sendo comunicado. (GOMES, 1994). Os questionários articulados a outras fontes de pesquisa, como os projetos pedagógicos dos cursos e os planos de ensino das disciplinas, têm a finalidade de adensar o processo investigativo.

A região Centro-Oeste do Brasil é composta pelos estados de Goiás, Mato Grosso, Mato Grosso do Sul e o Distrito Federal. Nela estão situadas cinco Universidades Federais: Universidade Federal de Goiás - UFG, Universidade Federal de Mato Grosso - UFMT, Universidade Federal da Grande Dourados - UFGD, Universidade Federal de Mato Grosso do Sul - UFMS e Universidade de Brasília- UnB.

Juntas essas universidades oferecem 104 cursos de Licenciatura, na área de Ciências Humanas. No decorrer da pesquisa, os projetos pedagógicos e/ou matrizes curriculares e/ou resoluções de criação desses cursos foram examinados a fim de se identificar e mapear as

\footnotetext{
${ }^{6}$ DIALlO, Cíntia Santos. História da África e a Cultura Afro-brasileira no Ensino Superi-or Público: análises sobre currículos e disciplinas dos cursos de licenciatura em História em Mato Grosso do Sul (2003-2016). 3017. 347 f. Tese (Doutorado em História) - Universidade Federal da Grande Dourados/MS, 2017. 
disciplinas que nomeadamente abordam a temática. Posteriormente foi realizada a análise das respectivas ementas e bibliografias.

\section{DIALOGANDO COM A HISTÓRIA DA EDUCAÇÃO}

O desenvolvimento desta pesquisa tem como apoio a História da Educação, especificamente um campo teórico-metodológico que se estabeleceu a partir da década de 1990, com os estudos de Chervel (1990), Julia (2001), Goodson (1998) e Viño (2008). Essa área é denominada História das Disciplinas Escolares.

Embora os estudos de Chervel (1990) tenham se centrado na história das disciplinas do ensino elementar e secundário, a metodologia utilizada por ele pode nos auxiliar também na análise das disciplinas acadêmicas. Para o autor, o "objetivo da história das disciplinas escolares é a pesquisa ou a determinação exata das finalidades que lhe correspondem" (CHERVEL, 1990, p. 15). Tal referencial pode, portanto, contribuir para a compreensão da penetração da temática nos cursos de licenciatura, por meio das disciplinas analisadas na pesquisa.

O autor chama atenção para três problemas que envolvem a construção da história de uma disciplina: o primeiro diz respeito ao mapeamento e análise de sua gênese, ou seja, em quais condições a disciplina foi produzida e/ou introduzida no sistema de ensino, bem como quais interesses políticos, econômicos e sociais ela reflete. O segundo problema refere-se à finalidade de tal disciplina, ou seja, em que medida atende ou não as expectativas para as quais foi criada. O último problema consiste na descrição e análise do funcionamento da disciplina, desde sua organização quanto aos conteúdos, ementas e carga horária, passando pelas características do corpo docente, indo até os efeitos emancipadores ou conservadores sobre os alunos e a sociedade (CHERVEL, 1990).

Nessa perspectiva, cujo objeto de análise são as disciplinas, a problemática está intimamente ligada a três aspectos: I) à sua gênese, que se funda na singularidade da obrigatoriedade do ensino da História da África e da cultura dos afro-brasileiros na Educação Básica e Educação das Relações Étnico-raciais, o que gerou a necessidade da inclusão e/ou reestruturação de disciplinas específicas na grade curricular dos cursos de licenciatura para complementar a formação inicial de professores; II) à finalidade da disciplina, que nos remete às possibilidades e limites de uma disciplina (ou conjunto delas) que pretende formar professores para a atuação na Educação Básica, na perspectiva de romper com a concepção estigmatizada e racista do continente africano, dos negros brasileiros, da diáspora e, ao mesmo tempo, contribuir com a construção de um projeto de sociedade mais justo, no qual as diferenças étnicas e raciais sejam respeitadas, reconhecidas e valorizados; e, por fim, III) ao funcionamento 
da disciplina sobre a história da África e temáticas correlatas, em face das disputas por espaço e tempo no projeto pedagógico do curso, bem como pela disponibilidade de recursos materiais e humanos.

A pesquisa sobre a história de uma disciplina exige que o historiador se debruce sobre um número diversificado e denso de fontes, como legislação, projetos pedagógicos, planos de aula, ementas, bibliografias, projeto de pesquisa de professores, diretrizes curriculares, pareceres dos conselhos de educação e impressos, além das entrevistas produzidas a partir do contato com professores, coordenadores de cursos e alunos (GATTI JÚNIOR, s/d).

\section{DIALOGANDO COM A DECOLONIALIDADE}

Buscamos em Lander (2005) elementos para a compreensão do processo de subalternização dos saberes latinoamericanos, africanos e locais aos saberes europeus.

Para além de um modelo econômico, o neoliberalismo é, no espaço deste trabalho, entendido como um "discurso hegemônico de um modelo civilizatório", que orienta a racionalidade da sociedade liberal moderna e normatiza os padrões de produção da existência humana. Esse discurso, que nasce com a Modernidade, estabeleceu-se como parâmetro de validação ou negação de todo e qualquer processo civilizatório periférico.

Lander (2005) explica que a força desse pensamento hegemônico está na extraordinária capacidade de "naturalizar as relações sociais", ou seja, a ideia de que a organização social, política e econômica das sociedades classificadas como modernas é o único modelo ou caminho, enfim, a ser seguido para se alcançar "uma ordem social desejável” (p. 8). Isso implica, segundo o autor,

[...] uma concepção segundo a qual nos encontramos numa linha de chegada, sociedade sem ideologias, modelo civilizatório único, globalizado, universal que torna desnecessária a política na medida em que já não há alternativas possíveis a este modo de vida. (p. 8)

Para Lander (2005), as alternativas ao projeto societário moderno, com sua característica “excludente" e "desigual", requerem um movimento de desconstrução "do caráter universal e natural da sociedade capitalista-liberal", ou seja, passam pelo questionamento da pretensa “objetividade e neutralidade dos principais instrumentos de naturalização e legitimação dessa ordem social”, quais sejam, "o conjunto de saberes que conhecemos globalmente como ciências sociais". Isso significa colocar em "xeque" todos os pressupostos teóricos e metodológicos que orientam a sociedade moderna liberal na atualidade, ao mesmo tempo em que invalidam, negam e excluem outras nações, povos e culturas. 
No que tange aos projetos contra-hegemônicos, é possível observar, nas últimas décadas, um crescente "vigoroso e multifacetado" movimento de desconstrução do pensamento hegemônico. Nesse movimento destacam-se: "as múltiplas vertentes da crítica feminista"; “o questionamento da história europeia como História Universal"; o "desentranhamento da natureza do orientalismo"; a "exigência de abrir as ciências sociais"; as contribuições dos estudos subalternos da Índia"; "a produção de intelectuais africanos"; a "chamada perspectiva pós-colonial" e as perspectivas do saber não eurocêntrico desenvolvidas por pesquisadores latinoamericanos (LANDER, 2005).

Em diálogo com Lander, entendemos que os conteúdos sobre saberes, narrativas, cosmogonias afro-brasileiras e africanas veiculadas por meio de disciplinas específicas, além das transversalidades em diferentes disciplinas, podem provocar rupturas e deslocamentos epistemológicos que questionem o currículo monocultural.

\section{O PAPEL INDUTOR DAS INSTITUIÇÕES DE ENSINO SUPERIOR}

Respeitada a autonomia universitária, as DCNERER (2004) indicam que as Instituições de Ensino Superior, por meio do ensino, da pesquisa e da extensão, têm um papel importante na construção de novas narrativas que contribuam com a desconstrução da história que estigmatiza, subalterna, desvaloriza e invisibiliza as múltiplas maneiras de ser, existir, sentir e produzir do africano e do afro-brasileiro.

As Instituições deverão, pois, providenciar o registro das narrativas não contadas sobre remanescentes dos quilombos rurais e urbanos, bem como de outras sociedades e/ou comunidades africanas e afro-brasileiras, do passado e do presente, além de subsidiar os professores da Educação Básica na elaboração de projetos e planos de aula que abordem a temática em tela, bem como produzir o mapeamento e a divulgação de experiências pedagógicas exitosas.

Deve ainda ser produzido um diagnóstico das principais dificuldades dos professores para incorporar às suas práticas pedagógicas a História e Cultura afro-brasileira e africana e a Educação para as Relações Étnico-raciais. As DCNERER sugerem que os caminhos possíveis para a superação de tais dificuldades devem ser construídos a partir de articulações com os sistemas de ensino, com os pesquisadores da área, com os Núcleos de Estudos Afro-brasileiros (Neab) e com os militantes do movimento negro, visando também à produção de material didático e à formação de professores. (Brasil, 2004).

Quatro orientações, em especial, preconizadas nas DCNERER, justificam e impulsionam a presente pesquisa: 
- Introdução, nos cursos de formação de professores e de outros profissionais da educação: de análises das relações sociais e raciais no Brasil; de conceitos e de suas bases teóricas, tais como racismo, discriminações, intolerância, preconceito, estereótipo, raça, etnia, cultura, classe social, diversidade, diferença, multiculturalismo; de práticas pedagógicas, de materiais e de textos didáticos, na perspectiva da reeducação das relações étnico-raciais e do ensino e aprendizagem da História e Cultura dos Afrobrasileiros e dos Africanos.

- Inclusão de discussão da questão racial como parte integrante da matriz curricular, tanto dos cursos de licenciatura para Educação Infantil, os anos iniciais e finais da Educação Fundamental, Educação Média, Educação de Jovens e Adultos, como de processos de formação continuada de professores, inclusive de docentes no Ensino Superior.

- Inclusão, respeitada a autonomia dos estabelecimentos do Ensino Superior, nos conteúdos de disciplinas e em atividades curriculares dos cursos que ministra, de Educação das Relações Étnico-Raciais, de conhecimentos de matriz africana e/ou que dizem respeito à população negra. Por exemplo: em Medicina, entre outras questões, estudo da anemia falciforme, da problemática da pressão alta; em Matemática, contribuições de raiz africana, identificadas e descritas pela Etno-Matemática; em Filosofia, estudo da filosofia tradicional africana e de contribuições de filósofos africanos e afrodescendentes da atualidade.

- Inclusão de bibliografia relativa à história e cultura afro-brasileira e africana às relações étnico-raciais, aos problemas desencadeados pelo racismo e por outras discriminações, à pedagogia antirracista nos programas de concursos públicos para admissão de professores. (BRASIL, 2004, p.23) (grifos nossos)

Em linhas gerais, é a complexidade das relações raciais, a reeducação das relações raciais, a história da África e dos afro-brasileiros e as bibliografias relativas a esses temas que buscamos com o exame detalhado das matrizes curriculares dos cursos de licenciatura na região Centro-Oeste do Brasil.

\section{A PROCURA DAS DISCIPLINAS}

Tendo em vista o volume de cursos e disciplinas a serem investigados, optamos por fazer busca nos sítios eletrônicos oficiais de cada IES ${ }^{7}$, de modo que foi possível identificar e elencar todos os cursos de licenciatura na área das Ciências Humanas oferecidos pelas Instituições pesquisadas.

A identificação dos cursos não foi suficiente para que se encontrassem as disciplinas cuja temática contemplassem o objeto da pesquisa. Para tanto, foi necessário localizar as páginas eletrônicas dos cursos e buscar documentos oficiais, como projetos pedagógicos e/ou resoluções sobre a oferta de disciplinas como ementas, objetivos, bibliografias e conteúdo programático, nos quais pudéssemos identificar disciplinas e conteúdos relacionados com a

\footnotetext{
${ }^{7} \mathrm{O}$ acesso aos sítios eletrônicos foi realizado entre nos meses de agosto/2018 a outubro/2018.
} 
História e Cultura afro-brasileira e africana. Ao final da busca, chegamos ao quantitativo de 05 Universidades, que juntas ofertam 104 disciplinas com temáticas relacionas à pesquisa.

A região Centro-Oeste possui cinco Instituições Federais Públicas de Ensino Superior:

a. Universidade de Brasília (UnB) - Distrito Federal.

b. Universidade de Goiás (UFG) - Goiás.

c. Universidade Federal de Mato Grosso (UFMT) - Mato Grosso.

d. Universidade Federal de Mato Grosso do Sul (UFMS) - Mato Grosso do Sul.

e. Universidade Federal da Grande Dourados (UFGD) - Mato Grosso do Sul.

Os quadros que seguem trazem informações sobre as licenciaturas ofertadas por cada IES e as disciplinas que contemplam a temática da pesquisa, quando for o caso. A expressão “Não atende" é utilizada para informar que no projeto pedagógico e/ou resolução não há nenhuma disciplina obrigatória que contemple a História e Cultura da África e dos afrobrasileiros e/ou a Educação das Relações Étnico-raciais. A expressão "Não está disponível no site $^{8}$ " é utilizada para informar que o projeto pedagógico do curso não está disponível na versão on line.

\section{Universidade de Brasília - UnB}

A Universidade de Brasília possui 11 cursos de licenciatura, dos quais apenas o curso de História atende à legislação e traz na sua Matriz Curricular a disciplina de História da África. O curso de Artes Visuais não disponibiliza em sua página o projeto pedagógico. Os outros 9 cursos, entre eles os de Pedagogia e Letras, não atendem em disciplinas específicas a temática objeto desta pesquisa. (Quadro 1)

Quadro 1 - Cursos e Disciplinas Universidade de Brasília - UNB

\begin{tabular}{|c|c|c|}
\hline Campus/Unidade & Curso & Disciplina \\
\hline Planaltina & 1. Educação do Campo & Não atende \\
\hline \multirow{9}{*}{ Darcy Ribeiro } & 2. Artes Cênicas & Não atende \\
\hline & 3. Artes Visuais & Não está disponível no site \\
\hline & 4. Educação Física & Não atende \\
\hline & 5. Filosofia & Não atende \\
\hline & 6. Geografia & Não atende \\
\hline & 7. História & História da África \\
\hline & 8. Letras - Português & Não atende \\
\hline & 9. Letras - Espanhol & Não atende \\
\hline & 10. Música & Não atende \\
\hline
\end{tabular}

\footnotetext{
${ }^{8}$ Nesses casos foi solicitado por meio do e-SIC (Sistema Eletrônico do Serviço de Informações ao Cidadão) o projeto pedagógico do curso. Até a conclusão deste artigo não havíamos recebido a resposta a nossa solicitação. 


\begin{tabular}{|l|l|l|}
\hline & 11. Pedagogia & Não atende \\
\hline
\end{tabular}

Produzidos pelas pesquisadoras/2018

\section{UNIVERSIDADE DE GOIÁS - UFG}

A Universidade Federal de Goiás oferece, em diferentes Campi, o total de 29 licenciaturas. O curso de História Catalão traz em sua Matriz Curricular duas disciplinas: História das Populações Negras e Indígenas na Sociedade Brasileira e História da Antiguidade Oriental. ${ }^{9}$ Já o mesmo curso ofertado em Jataí e Goiânia oferecem a disciplina de História e Cultura Afro-brasileira e Africana. O curso de Geografia de Jataí oferece a disciplina de Geografia e Relações Étnico-raciais. O curso de Artes Visuais de Goiânia, nas disciplinas de História da Arte, da Pré-História ao Barroco, e da História da Arte, no Brasil e na América Latina, faz referência, em seus conteúdos, respectivamente à Arte Africana e à Afro-brasileira. Os cursos de Educação Física de Catalão: Artes Cênicas, Educação Intercultural, Filosofia e Música de Goiânia não disponibilizaram suas páginas, os projetos pedagógicos. Os demais 19 cursos não atendem às demandas específicas da Educação Étnico-racial (quadro2)

Quadro 2 - Cursos e Disciplinas - Universidade de Goiás - UFG

\begin{tabular}{|c|c|c|}
\hline Campus/Unidade & Curso & Disciplina \\
\hline \multirow{8}{*}{ Catalão } & 1. Ciências Sociais & Não atende \\
\hline & 2. Educação Física & Não informado no site \\
\hline & 3. Geografia & Não atende \\
\hline & \multirow{2}{*}{ 4. História } & $\begin{array}{l}\text { História das Populações } \\
\text { Negras e Indígenas na } \\
\text { Sociedade Brasileira }\end{array}$ \\
\hline & & $\begin{array}{c}\text { História da Antiguidade } \\
\text { Oriental }\end{array}$ \\
\hline & 5. Letras/Português & Não atende \\
\hline & 6. Letras/Inglês & Não atende \\
\hline & 7. Pedagogia & Não atende \\
\hline \multirow{4}{*}{ Jataí } & 8. Educação Física & Não atende \\
\hline & 9. Geografia & $\begin{array}{c}\text { Geografia e Relações } \\
\text { Étnico-Raciais }\end{array}$ \\
\hline & 10. História & $\begin{array}{l}\text { História e Cultura Afro- } \\
\text { Brasileira }\end{array}$ \\
\hline & 11. Letras/Inglês & Não atende \\
\hline
\end{tabular}

9 Os conteúdos da disciplina abarcam temas referentes à História da África Pré-Colonial, como poderemos observar no capítulo em que faremos análise dos conteúdos formativos de cada disciplina. 


\begin{tabular}{|c|c|c|}
\hline & 12. Letras/Português & Não atende \\
\hline & 13. Pedagogia & Não atende \\
\hline \multirow{17}{*}{ Goiânia } & 14. Artes Cênicas & $\begin{array}{l}\text { Não está disponível no } \\
\text { site }\end{array}$ \\
\hline & \multirow{2}{*}{ 15. Artes Visuais } & $\begin{array}{c}\text { História da Arte: da Pré- } \\
\text { História ao Barroco }\end{array}$ \\
\hline & & $\begin{array}{c}\text { História da Arte: no Brasil } \\
\text { e na América Latina }\end{array}$ \\
\hline & 16. Ciências Sociais & Não atende \\
\hline & 17. Dança & Não atende \\
\hline & 18. Educação Física & Não atende \\
\hline & 19. Educação Intercultural & $\begin{array}{l}\text { Não está disponível no } \\
\text { site }\end{array}$ \\
\hline & 20. Filosofia & $\begin{array}{l}\text { Não está disponível no } \\
\text { site }\end{array}$ \\
\hline & 21. Geografia & Não atende \\
\hline & 22. História & $\begin{array}{c}\text { História e Cultura Afro- } \\
\text { Brasileira }\end{array}$ \\
\hline & 23. Letras/Espanhol & Não atende \\
\hline & 24. Letras/Francês & Não atende \\
\hline & 25. Letras/Libras & Não atende \\
\hline & 26. Letras/Português & Não atende \\
\hline & 27. Letras/Inglês & Não atende \\
\hline & 28. Música & $\begin{array}{l}\text { Não está disponível no } \\
\text { site }\end{array}$ \\
\hline & 29. Pedagogia & Não atende \\
\hline
\end{tabular}

Produzido pelas pesquisadoras

\section{UNIVERSIDADE FEDERAL DE MATO GROSSO - UFMT}

A Universidade Federal de Mato Grosso oferece, em seus três campi, 20 licenciaturas. No da cidade de Cuiabá, no curso de Educação Física existe a disciplina de Cultura Afrobrasileira. Já nos de Geografia e Pedagogia é ofertada a disciplina de Educação das Relações Étnico-raciais. No curso de História, a disciplina de História da África. Em Rondonópolis, o curso de História oferece a disciplina de História da África. Os outros 15 curso não atendem ao especificado. (Quadro 3)

Quadro 3 - Cursos e Disciplinas - Universidade Federal de Mato Grosso UFMT

\begin{tabular}{|c|cl|c|}
\hline Campus/Unidade & \multicolumn{1}{|c|}{ Curso } & Disciplina \\
\hline \multirow{4}{*}{ Cuiabá } & 1. & Educação Física & Cultura Afro-Brasileira \\
\cline { 2 - 4 } & 2. & Filosofia & Não atende \\
\cline { 2 - 4 } & 3. & Geografia & Educação das Relações Étnico-Raciais \\
\cline { 2 - 4 } & 4. & História & História da África \\
\cline { 2 - 4 } & 5. & Letras/Espanhol & Não atende \\
\cline { 2 - 4 } & 6. & Letras/Francês & Não atende \\
\hline
\end{tabular}




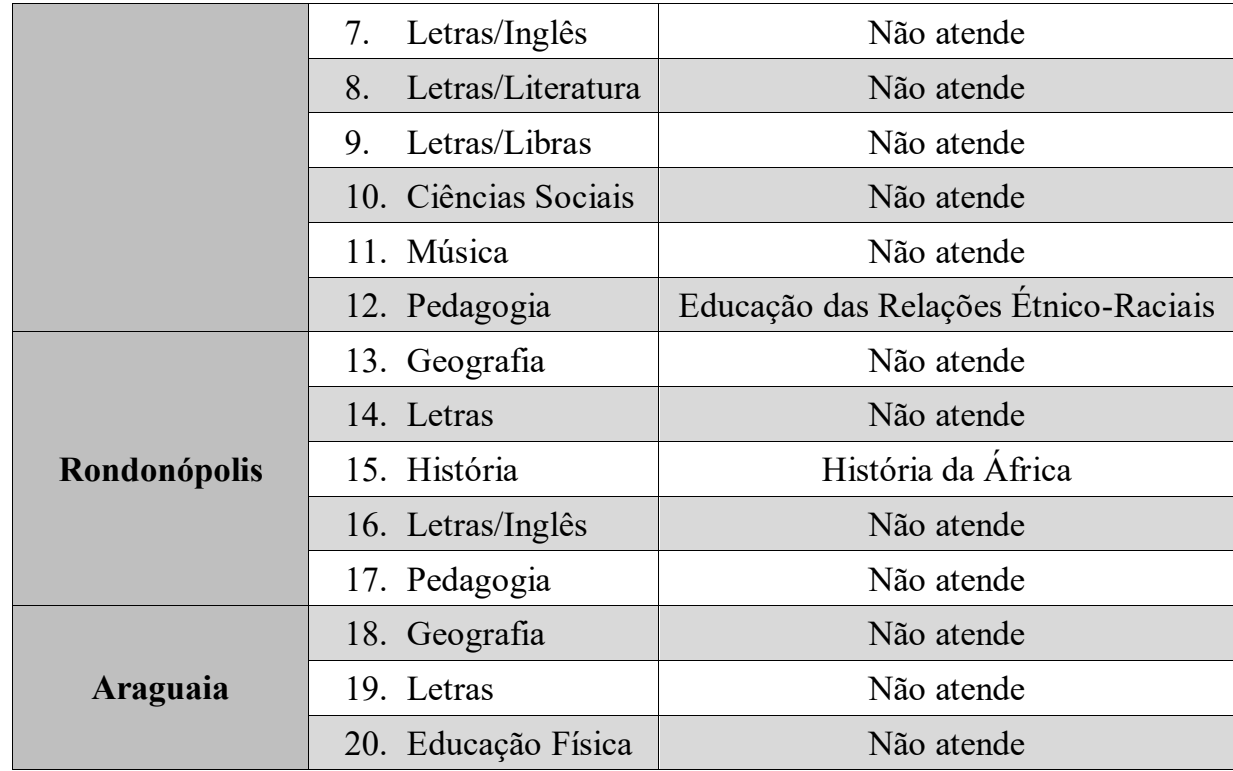

Produzido pelas pesquisadoras

\section{UNIVERSIDADE FEDERAL DE MATO GROSSO DO SUL - UFMS}

A Universidade Federal de Mato Grosso do Sul oferece, em diferentes Campi, 34 cursos de licenciatura, dos quais apenas 5 não atendem à temática Étnico-racial. Vale destacar que a disciplina de História da África e Cultura Brasileira é ofertada nos cursos de Letras, como a de Educação das Relações Étnico-raciais é ofertada nos cursos de Educação Física e Filosofia. (Quadro 4)

Quadro 4 - Cursos e Disciplinas -Universidade Federal de Mato Grosso do Sul - UFMS

\begin{tabular}{|c|c|c|}
\hline Campus/Unidade & Curso & Disciplina \\
\hline \multirow{9}{*}{ Aquidauana } & \multirow[t]{2}{*}{ 1. Geografia } & $\begin{array}{c}\text { História da África e Cultura Afro- } \\
\text { Brasileira }\end{array}$ \\
\hline & & História da África \\
\hline & \multirow{2}{*}{ 2. História } & $\begin{array}{c}\text { História da África e Cultura Afro- } \\
\text { Brasileira }\end{array}$ \\
\hline & & $\begin{array}{c}\text { Educação das Relações Étnico- } \\
\text { Raciais }\end{array}$ \\
\hline & $\begin{array}{l}\text { 3. Letras - } \\
\text { Português/Literatura }\end{array}$ & $\begin{array}{c}\text { História e Cultura Afro-Brasileira } \\
\text { e Africana }\end{array}$ \\
\hline & $\begin{array}{l}\text { 4. Letras - } \\
\text { Português/Inglês }\end{array}$ & $\begin{array}{c}\text { História e Cultura Afro-Brasileira } \\
\text { e Africana }\end{array}$ \\
\hline & $\begin{array}{l}\text { 5. Letras - } \\
\text { Português/Espanhol }\end{array}$ & $\begin{array}{c}\text { História e Cultura Afro-Brasileira } \\
\text { e Africana }\end{array}$ \\
\hline & 6. Licenciatura Indígena & $\begin{array}{c}\text { História e Antropologia Indígena } \\
\text { e Afro-Brasileira }\end{array}$ \\
\hline & 7. Pedagogia & $\begin{array}{c}\text { Educação das Relações Étnico- } \\
\text { Raciais }\end{array}$ \\
\hline Coxim & 8. História & $\begin{array}{c}\text { História da África e Cultura Afro- } \\
\text { Brasileira }\end{array}$ \\
\hline
\end{tabular}




\begin{tabular}{|c|c|c|}
\hline & 9. Letras & $\begin{array}{c}\text { História da África e Cultura Afro- } \\
\text { Brasileira }\end{array}$ \\
\hline Nova Andradina & 10. História & $\begin{array}{c}\text { História e Cultura Afro-Brasileira } \\
\text { e Africana }\end{array}$ \\
\hline \multirow[b]{2}{*}{ Naviraí } & 11. Ciências Sociais & $\begin{array}{c}\text { Estudos Afro-Brasileiros e étnico- } \\
\text { raciais }\end{array}$ \\
\hline & 12. Pedagogia & $\begin{array}{c}\text { Tópicos Educacionais em } \\
\text { Educação e Igualdade Étnico- } \\
\text { Raciais }\end{array}$ \\
\hline \multirow{7}{*}{ Pantanal } & 13. Educação Física & $\begin{array}{c}\text { Teorias Pedagógicas na Educação } \\
\text { Física }\end{array}$ \\
\hline & 14. Geografia & Não atende \\
\hline & \multirow[b]{2}{*}{ 15. História } & História da África \\
\hline & & $\begin{array}{c}\text { Educação das Relações Étnico- } \\
\text { Raciais }\end{array}$ \\
\hline & 16. Letras/Inglês & $\begin{array}{c}\text { Educação das Relações Étnico- } \\
\text { Raciais }\end{array}$ \\
\hline & 17. Letras/Espanhol & $\begin{array}{c}\text { Educação das Relações Étnico- } \\
\text { Raciais }\end{array}$ \\
\hline & 18. Pedagogia & Não atende \\
\hline Ponta Porã & 19. Pedagogia & Não atende \\
\hline \multirow{7}{*}{ Três Lagoas } & 20. Geografia & Cultura e Relações Étnico-Raciais \\
\hline & \multirow{2}{*}{ 21. História } & Introdução à História da África \\
\hline & & $\begin{array}{l}\text { Prática de Ensino e Pesquisa em } \\
\text { História: Multiculturalismo }\end{array}$ \\
\hline & 22. Letras/Espanhol & $\begin{array}{c}\text { Educação das Relações Étnico- } \\
\text { Raciais }\end{array}$ \\
\hline & 23. Letras/Inglês & $\begin{array}{c}\text { Educação das Relações Étnico- } \\
\text { Raciais }\end{array}$ \\
\hline & 24. Letras/Literatura & $\begin{array}{c}\text { Educação das Relações Étnico- } \\
\text { Raciais }\end{array}$ \\
\hline & 25. Pedagogia & $\begin{array}{c}\text { Teoria e Prática em Diversidade } \\
\text { Étnico-Racial }\end{array}$ \\
\hline \multirow{3}{*}{ Campo Grande } & 26. Filosofia & $\begin{array}{c}\text { Educação das Relações Étnico- } \\
\text { Raciais }\end{array}$ \\
\hline & \multirow{2}{*}{ 27. História } & $\begin{array}{c}\text { Ensino de História e Cultura Afro- } \\
\text { Brasileira e Africana }\end{array}$ \\
\hline & & $\begin{array}{c}\text { Educação das Relações Étnico- } \\
\text { Raciais }\end{array}$ \\
\hline
\end{tabular}




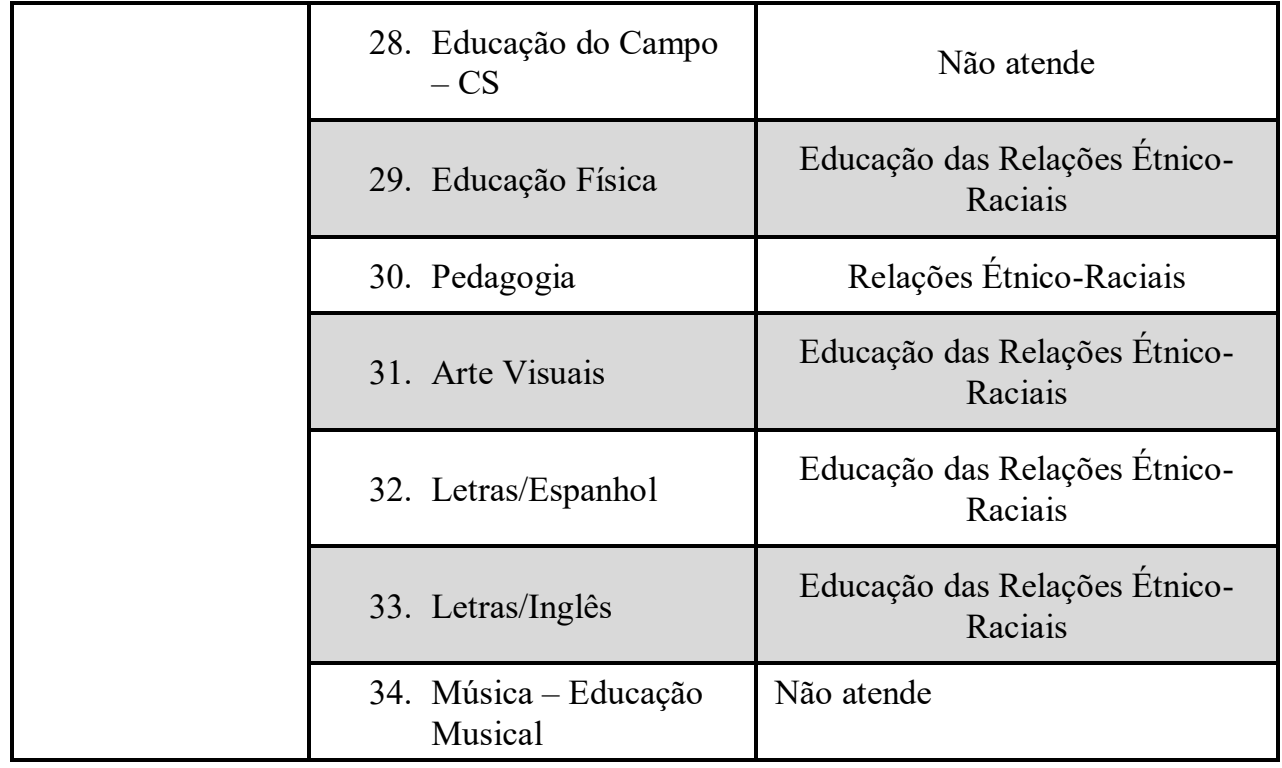

Produzido pelas pesquisadoras

\section{Universidade Federal da Grande Dourados - UFGD}

A Universidade Federal da Grande Dourados é a única entre as universidades pesquisadas em que os cursos de licenciatura oferecem disciplinas cujos conteúdos formativos tratam de maneira geral a História e Cultura Afro-brasileira e africana e a Educação das Relações Étnico-raciais. (Quadro 5)

Quadro 5 - Cursos e Disciplina - UFGD

\begin{tabular}{|c|cl|}
\hline \multirow{2}{*}{ Curso } & \multicolumn{2}{|c|}{ Disciplina } \\
\hline Artes Cênicas & 1. & Tópicos em Cultura e Diversidade Étnico-Racial \\
\hline Ciências Sociais & 2. & Tópicos em Cultura e Diversidade Étnico-Racial \\
\hline Educação Física & 3. & Tópicos em Cultura e Diversidade Étnico-Racial \\
\hline \multirow{2}{*}{ Geografia } & 4. & Geografia da África \\
\cline { 2 - 3 } & 5. & Tópicos em Cultura e Diversidade Étnico-Racial \\
\hline \multirow{2}{*}{ História } & 6. & História da África \\
\cline { 2 - 3 } & 7. & História da África e Ásia Contemporâneas \\
\cline { 2 - 3 } & 8. & Tópicos em Cultura e Diversidade Étnico-Racial \\
\hline \multirow{2}{*}{ Letras } & 9. & Tópicos em Cultura e Diversidade Étnico-Racial \\
\hline Pedagogia & 10. & Tópicos em Cultura e Diversidade Étnico-Racial \\
\hline
\end{tabular}

Produzido pelas pesquisadoras

Preliminarmente é possível considerar que dos 104 cursos, pouco menos da metade, 50 cursos contemplam em suas matrizes curriculares conteúdos referentes à História e Cultura afro-brasileira e africana e à Educação das Relações Étnico-raciais, com destaque para os cursos de História, pois todos eles oferecem pelo menos uma disciplina sobre o assunto. O gritante silenciamento de 48 cursos com relação à temática objeto da pesquisa explica em parte o 
recorrente discurso dos professores da Educação Básica sobre a fragilidade em sua formação inicial para discutir a temática. (Quadro 5)

Quadro 5- Relação entre disciplina/curso

\begin{tabular}{|c|c|c|c|c|}
\hline UNIVERSIDADE & Cursos & C/disciplina $^{\mathbf{1 0}}$ & S/ disciplina $^{\mathbf{1 1}}$ & $\begin{array}{c}\text { Não } \\
\text { Informado }^{\text {Undor }}\end{array}$ \\
\hline UNB & 11 & 1 & 9 & 1 \\
\hline UFG & 29 & 5 & 19 & 5 \\
\hline UFMT & 20 & 5 & 15 & 0 \\
\hline UFMS & 34 & 29 & 5 & 0 \\
\hline UFGD & 10 & 10 & 0 & 0 \\
\hline & 104 & 50 & 48 & 6 \\
\hline
\end{tabular}

Produzido pelas pesquisadoras

Outras questões se colocam, talvez menos evidentes e mais subterrâneas, com respeito ao porquê de em 15 anos de vigência da lei os cursos que tiveram seus Projetos Pedagógicos reformulados ainda negligenciam a temática? No campo de disputa pela formulação/reformulação curricular das Licenciaturas, quais são as vozes que ecoam? Quais são silenciadas?

Constata-se que 48 cursos ainda não incorporam a história e a cultura afro-brasileira e africana e a Educação das Relações Étnico-raciais em seus itinerários formativos. Consideramos ainda, preliminarmente, que as temáticas nas IES pesquisadas estão em condições semiperiféricas/negligenciadas.

No que concerne aos Projetos Político-pedagógicos dos cursos nas IES, os debates prolongados e a real inclusão de temas relacionados com a organização de disciplinas que tratam da educação e das relações étnico-raciais e seus conteúdos específicos enfrentam resistências institucionais envoltas em arraigadas questões sociais e culturais. Essas questões, por vezes presentes nas atividades administrativas, passam anos sendo confrontadas quanto à necessidade desse "tipo" de conhecimento ou formação na formação de professores. Não se reconhece que e vivemos em um país com massiva miscigenação afrodescente.

As consequências dessas ausências na formação inicial de professores para a Educação Básica podem ser sentidas, por um lado, na impossibilidade de o professor produzir práticas pedagógicas que provoquem deslocamentos epistêmicos que desafiem a lógica hegemônica do currículo monocultural. Por outro lado, perpetua-se a hierarquização das narrativas e saberes que desprezam os conhecimentos produzidos fora do eixo euroestadunidense.

\footnotetext{
${ }^{10}$ Com a disciplina

${ }^{11}$ Sem a disciplina 


\section{SOBRE PRESENÇAS E AS AUSÊNCIAS...}

No escopo da pesquisa, foi possível evidenciar a penetração da temática em tela, nas licenciaturas, por meio da presença das disciplinas específicas, ainda que não seja possível alcançar seus desdobramentos na prática cotidiana dos professores recém-formados, pois não fizemos esse cruzamento. A existência de tais disciplinas não apenas sugere o atendimento às diretrizes, mas aponta ainda a capacidade de organização, força e tensionamento das culturas negadas por maior espaço nos currículos, graças aos movimentos acadêmicos, escolares e sociais.

Não podemos deixar de considerar que a presença da temática em disciplinas específicas em 50 cursos de licenciatura é decorrente, também, da volumosa produção e difusão de conhecimentos sobre África, afro-brasileiros e temas correlatos, elaborada durante os últimos 15 anos.

De acordo com Gomes (2012, p. 102), "os ditos excluídos começam a reagir de forma diferente: lançam mão de estratégias coletivas e individuais. Articulam-se em rede". A autora prossegue explicando que, concomitante às novas formas capitalistas de exploração, surgem projetos contra-hegemônicos nascidos nos países do Sul, pensados por movimentos que não só denunciam as formas de exclusão promovidas pelo capital, como propõem outros projetos societários, pautados na democracia, no direito e no respeito à diferença. Tais projetos, ao mesmo tempo em que questionam a validade do conhecimento hegemônico, reconhecem na incorporação de saberes periféricos subalternizados e negligenciados a possibilidade de se subverter a ordem e produzir a descolonização dos currículos escolar e acadêmico.

Não podemos negar que a presença da temática nas licenciaturas também se deve ao olhar sensível e atento dos professores dos cursos para a complexidade das relações raciais no Brasil e para as lacunas historiográficas, bem como para a necessidade de pensá-las no âmbito dos cursos de formação de professores.

É importante destacar que todos os cursos da História da região possuem disciplina específica sobre a História da África, com conteúdos variados, conforme podemos observar nas ementas citadas abaixo:

\footnotetext{
As sociedades primitivas africanas. As grandes civilizações do Rio Nilo. A influência das religiões islâmicas sobre a África. Colonização europeia. Escravidão negra. Processo de descolonização. Insurreições. Apartheid. África no mundo contemporâneo (Ementa da Disciplina História da África - Curso de História CPAN/UFMS)

O continente africano. Sociedade, política e religiosidade na África centro-ocidental (séculos X a XIV). A oralidade nas sociedades africanas. Conquista e colonização da África pelos europeus. Os luso-brasileiros e europeus na África. Escravidão e tráfico.
} 
Sociedade, política e cotidiano no século XVIII. (Ementa da Disciplina História da África - Curso História UFGD)

Estudo das diferentes estruturas sócio-políticas da África entre os séculos XVI e XX, os processos de constituição dos sistemas coloniais e de descolonização e as formas de abordagens didático-pedagógicas. (Ementa da disciplina História da África - Curso de História Cuiabá/UFMT)

Panorama cartográfico, histórico e arqueológico do continente africano. Geo-história africana: topônimos, etnôminos, territorialidades. Colonização, colonialismo e descolonização. A historiografia da África: panorama e especificidade de fontes. Diáspora africana no Atlântico. (Ementa da disciplina História e Cultura afrobrasileira - Curso de História Regional Goiânia/UFG)

História da diversidade e multiplicidade africanas. Discussão teórica e metodológica para a construção da História da África, sua importância para a História e para as sociedades atlânticas. Oralidade e memória na História. Identidade e territorialidade na construção do Mundo Atlântico através da participação ativa das diversas sociedades africanas. O comércio de escravos e a mestiçagem cultural proporcionada pelas migrações, espontâneas ou forçadas, de povos africanos e seus contatos externos. Historiografia africanista e as tendências de revisão e construção de uma nova historiografia sobre o tema. História africana na sala de aula e suas implicações político-sociais. (Ementa da disciplina História da África - curso de História Campus Darcy Ribeiro/UnB)

Uma disciplina de um ou, no máximo, dois semestres não é suficiente para dar conta da complexidade da História africana. É possível, todavia, aproximar e subsidiar o acadêmico de licenciatura, para que este possa incorporar às suas práticas pedagógicas futuras narrativas e saberes africanos.

As ementas apresentam um leque de conteúdos acadêmicos que envolvem desde a África antiga, pré-colonial, comércio de escravos, colonialismo e luta pela independência até diversidade religiosa e linguística étnica. Nessa perspectiva, constatamos que há um amplo diálogo com as DCNERER e a periodização da história africana proposta por Moore (2007), a saber:

o processo de construção dos primeiros estados agro-burocráticos da história, antiguidade núbio-egípcia, as invasões do exterior, a conquista e a colonização da África setentrional, tráfico negreiro intra-continental e transoceânico, o processo de desintegração dos espaços sócio-históricos constituídos, a conquista e colonização de todo continente africano, as lutas de libertação e descolonização da África, as lutas da pós-independência (p. 162-163).

As ementas abrem caminho para uma História da África que rompe com o lugar comum das narrativas sobre misérias, guerras e doenças e com a visão europeia sobre o continente. Elas se permitem um lançar de luz sobre outros aspectos históricos, como reinos do Mali, do Congo e do Zimbabwe, as perspectivas africanas da escravidão árabe-muçulmana e transoceânica, a colonização europeia, as lutas anticoloniais, o pan-africanismo, a organização social, política e econômica dos estados independentes, a diáspora africana, a diversidade étnica e cultural, a União dos Estados Africanos e a Comunidade da África Ocidental, entre outros temas. 
As principais ausências são sentidas nos cursos de Letras e Pedagogia. No que tange ao curso de Letras, de acordo com a Lei no. 10639/2003, os conteúdos sobre a História e Cultura africana e afro-brasileira deverão ser ministrados também nas disciplinas de Literatura. Por não incorporarem a temática, autores importantes para a compreensão da condição dos africanos e afro-brasileiros podem ficar de fora desses currículos formativos, como, por exemplo, a literatura infanto-juvenil afro-brasileira, que desafia padrões de beleza e ideais de felicidade como aqueles contidos em narrativas e contos de fadas, de autores como Aimée Cesaire, Leopold Senghor, Carolina de Jesus e Conceição Evaristo, entre outros.

Os estudos produzidos por Eliane Cavalleiro (2000) confirmaram a existência do preconceito e das práticas de discriminação racial e racismo na sociedade brasileira. A autora se debruçou sobre o espaço escolar, no qual verificou que as consequências de tais práticas produzem, em alunos negros

auto-rejeição, desenvolvimento de baixa auto-estima com ausência de reconhecimento de capacidade pessoal; rejeição ao seu outro igual racialmente; timidez, pouca ou nenhuma participação em sala de aula; ausência de reconhecimento positivo de seu pertencimento racial; dificuldades no processo de aprendizagem; recusa em ir à escola e, consequentemente, evasão escolar". (p. 12)

Por outro lado, para o aluno branco

a cristalização de um sentimento irreal de superioridade, proporcionando a criação de um círculo vicioso que reforça a discriminação racial no cotidiano escolar, bem como em outros espaços da esfera pública. Não há como negar que o preconceito e a discriminação raciais constituem um problema de grande monta para a criança negra, visto que essa sofre direta e cotidianamente maus tratos, agressões e injustiças, os quais afetam a sua infância e comprometem todo o seu desenvolvimento intelectual. (p. 13, 2000).

A gritante ausência da temática nos cursos de Pedagogia contribui para que os futuros professores da educação infantil e séries iniciais permaneçam omissos quando ao respeito e ao reconhecimento da diversidade racial na escola, além de perpetuar estereótipos e privilegiar a reprodução de narrativas alicerçadas no eurocentrismo.

A ausência de disciplinas específicas sobre a temática em 48 cursos dos 104 pesquisados corrobora a ideia de que o currículo é um espaço em disputa. Tal silenciamento revela que a temática está em processo de consolidação e não alcançou força suficiente para disputar espaço com as disciplinas tradicionais e conquistar um lugar nas matrizes curriculares de todos os cursos de licenciatura.

\section{CONSIDERAÇÕES FINAIS}

Em resposta ao questionamento título deste artigo: sim, parte significativa dos licenciandos sabe e viu a História e Cultura africana e afro-brasileira e a Educação das Relações 
Étnico-raciais nos cursos de licenciaturas oferecidos pelas Universidades Federais da região do Centro-Oeste. Ainda que não seja possível mensurar tais conteúdos, as análises das ementas sugerem que saberes, histórias, cosmovisões e modos de ser, existir e sentir são intensamente vividos por africanos e afro-brasileiros, mas que ainda são saberes subterrâneos para os currículos escolares, estando presentes apenas em 50 cursos de licenciatura.

É preciso considerar que a temática é um campo de pesquisa acadêmica em processo de consolidação no país. Para além disso, sua incorporação também enfrenta resistências, por parte de professores e licenciandos, decorrentes do racismo institucional. Destacamos que, desde a promulgação da Lei no.10.639/2003, poucos foram os concursos para ingresso no magistério superior específico para a área. Ou seja, o número de professores efetivos pesquisadores da área nas universidades ainda é pequeno. Assim, as disciplinas que abarcam os conteúdos por nós discutidos ao longo deste artigo estão, em muitos casos, sob a responsabilidade de professores de outras áreas e muitas vezes na condição de substitutos.

Apesar dos esforços desses profissionais, as mudanças constantes de professores gera uma determinada instabilidade no corpo da disciplina, em decorrência das inclusões e supressões de conteúdos de um semestre/ano para outro, num processo que popularmente se denomina "atirando para todo lado". Essa dinâmica também é responsável pela fragilidade na formação de professores para desenvolver práticas pedagógicas comprometidas com a educação das relações étnico-raciais.

A incorporação da temática pode mobilizar o questionamento, não apenas sobre a negligência/invisibilidade, como também sobre o quanto é cruel o sistema de hierarquização que se consubstancia no racismo e suas consequências, além de colocar em dúvida a validade da centralidade da história europeia. Enfim, consideramos que essas disciplinas podem potencialmente contribuir com a construção da reorientação epistemológica pautada na Interculturalidade Crítica, que questiona a racialização, a subalternização, a inferiorização e seus padrões de poder, e que, ao mesmo tempo, abarca diferentes culturas e histórias, buscando promover o diálogo de respeito e reconhecimento que implica modos outros de ser, sentir e existir.

\section{REFERÊNCIAS}

ALBERTI, V. Manual de história oral. Rio de Janeiro: FGV, 2004.

BRASIL. Lei $\mathrm{n}^{\mathrm{a}}$ 10.639, de 9 de janeiro de 2003. Diário Oficial da União de 10 de janeiro de 2003. 
. Conselho Nacional de Educação. Parecer CNE/CP 3/2004. Diretrizes curriculares nacionais para a educação das relações étnico-raciais e para o ensino de história e cultura afrobrasileira e africana. Brasília, 2004a.

Resolução CNE/CP 1/2004. Diretrizes curriculares nacionais para a educação das relações étnico-raciais e para o ensino de história e cultura afro-brasileira e africana. Brasília, 2004b.

DIALLO, C. S. História da África e a Cultura Afro-brasileira no Ensino Superior Público: análises sobre currículos e disciplinas dos cursos de licenciatura em História em Mato Grosso do Sul (2003-2016). 3017. 347 f. Tese (Doutorado em História) - Universidade Federal da Grande Dourados/MS, 2017.

DOMINGUES, P. Movimento negro brasileiro: alguns apontamentos históricos. Tempo, v. 12, n. 23, 2007.

GOMES, N. L. Relações étnico-raciais, educação e descolonização dos currículos. Currículo Sem Fronteiras, v.12, n.1, pp. 98-109, Jan/Abr 2012.

GOMES, R. Análise de dados em pesquisa quantitativa. MINAYO, M.C.S. Pesquisa social: teoria, método e atividade. Petrópolis: Editora Vozes. 1994. p. 67 - 79.

CAVALLEIRO, E. Do silêncio do lar ao silêncio escolar: racismo, discriminação na educação infantil. São Paulo: Contexto, 2000.

CHERVEL, A. História das disciplinas escolares: reflexões sobre um campo de pesquisa. Revista Teoria e Educação, Porto Alegre, n. 2, p. 177-229, 1990.

GATTI JÚNIOR, D. A história das disciplinas escolares no Brasil: análise dos aspectos teórico-metodológicos e da historiografia educacional, s/d. Disponível em:

$<$ http://www.fae.ufmg.br/portalmineiro/conteudo/externos/4cpehemg/Textos/pdf/1b_1.pdf $>$. Acesso: nov. 2018.

GOODSON, I. F. Currículo: teoria e história. Petrópolis: Vozes, 1998.

JULIA, D. A cultura escolar como objeto histórico. Revista brasileira de história da educação, n., jan./jun., p. 9-43, 2001.

LANDER, E. CASTRO-GÓMEZ, S. A colonialidade do saber : eurocentrismo e ciências sociais : perspectivas latino-americanas. Buenos Aires : CLACSO, 2005.

MINAYO, M. C. S. Ciência, técnica e arte: o desafio da pesquisa social. In: MINAYO, M.C.S (org). Pesquisa social: teoria, método e atividade. Petrópolis: Editora Vozes. 1994. p. 9 -30 .

MOORE, Carlos Wedderburn. Novas bases para o ensino da história da África no Brasil. Brasília: In: BRASIL MEC/SECAD Educação anti-racista: caminhos abertos pela Lei Federal n. 10.639/03. Brasília: MEC/SECAD, 2005. p. 133-166

OLIVEIRA, Luiz Fernandes de; CANDAU, Vera Maria Ferrão. Pedagogia decolonial e educação antirracista e intercultural no Brasil. Educ. rev., Belo Horizonte, v. 26, n. 1, p. 1540, Apr. 2010 . Disponível em:

$<$ http://www.scielo.br/scielo.php?script=sci_arttext\&pid=S0102-

$46982010000100002 \& \operatorname{lng}=\mathrm{en} \& \mathrm{nrm}=\mathrm{iso}>$. access on 27 June 2018.

http://dx.doi.org/10.1590/S0102-46982010000100002.

VIÑO, A. F. A história das disciplinas escolares. Revista brasileira de história da educação. n. 18, set./dez., p. 173-215, 2008. 
WALSH, Catherine. Interculturalidade, Crítica e Pedagogia Decolonial: in-surgir re-existir e re-viver. In: CANDAU V.M. (Org.) Educação Intercultural na América Latina: Entre concepções, tensões e propostas. Rio de Janeiro: 7 Letras, 2009.

www.ufg.br

www.ufgd.edu.br

www.ufms.br

www.ufmt.br

www.unb.br 